\title{
Pulp: Research in Temporary, Biodegradable Structures
}

\author{
STEPHANIE DAVIDSON
}

Ryerson University

Keywords: cast paper, pulp, recycled paper, monocoque, thin shell structures, biodegradable structures, ephemeral structures

This paper documents in-progress design research in temporary, biodegradable structures. The experimental, thin-shell monocoque structures have been cast using a variety of cellulose-based materials, and represent a sampling of the outcome of a studio taught at three different architecture schools to-date.

The work and the process of making the work serves as an example of how designers can take responsibility for both where the materials that they choose come from, and also, where they end up. Made of exclusively recycled paper, self-harvested fibers or fabric pulp, the structures have the capacity to biodegrade completely. The idea for the experimental structures came from witnessing the dumpsters overflowing with models and scrap material at the end of each semester. The conviction underlying the work is that mindful handling of resources should begin in architectural education if it is going to successfully make its way further into the discipline, profession and construction industry.

The design task shows students how materials are responsive and constantly changing; they are not static, fixed objects. Paper is a particularly ephemeral material, highly vulnerable to moisture. Designing something with an intentionally short lifespan, and witnessing how it can break-down and decay, introduces students to the transformative nature of materials, and shows how degradation and eventual decay could be a design strength.

Formally, the design research has, to-date, developed a range of small-scale studies and full-scale forms that defy straightforward typological classification. The geometries are imprecise and unpredictable and because they change as they disintegrate, the geometries are not describable as fixed things. The formal results can't be anticipated with a high degree of accuracy before they're actually constructed. In keeping with the low-waste ethos of the approach, formwork for each cast study is also kept to a minimum. This paper documents three sample full-scale outcomes of the research that employ different approaches to formwork.

\section{INTRODUCTION}

Longevity and resilience against the elements have become among the most prized characteristics in building materials. Materials and assemblies that require little maintenance, and that don't react to moisture or time, have become the standard in the building industry. Cellulose-based materials like wood - typically highly reactive to moisture when untreated - are given surface treatments or clad in layers to decrease their permeability or exposure to the elements. This research sees the vulnerability of cellulose-based materials to moisture as a potential, and aims to develop structures of eventual decay.

More specifically, this documentation describes approaches to using a variety of cellulose-based materials, both found/recycled and self-harvested, to cast thin-shell or monocoque structures. The work is experimental and has very little precedent. It embraces the vulnerability of cellulose material to moisture and the elements, and views the inevitable disintegration and decay of the cast paper shells as a strength. The work asks designers to see materials as responsive and constantly transforming, and to take responsibility for where materials come from and where they end up. The work is formally provocative because of the informal and irregular nature of the thinshell paper structures, and because of the process of disintegration which brings its own constantly changing formal expression.

This paper will describe a variety of approaches taken to-date in: sourcing materials for the cast paper shells, studying the composition and physical structure of the materials, making pulp, casting paper swatches, scaling-up to cast three foot spans, and finally, scaling-up to cast a room-size monocoque shell enclosure.

Three examples of room-size shells will demonstrate different ways of working with the constraint of minimal formwork; in the spirit of the research, formwork, which often adds unnecessary waste in a construction process, had to be handled with the spirit of material economy and biodegradability.

To-date, the research studio has been taught four times at three different architecture schools: the Peter Behrens 


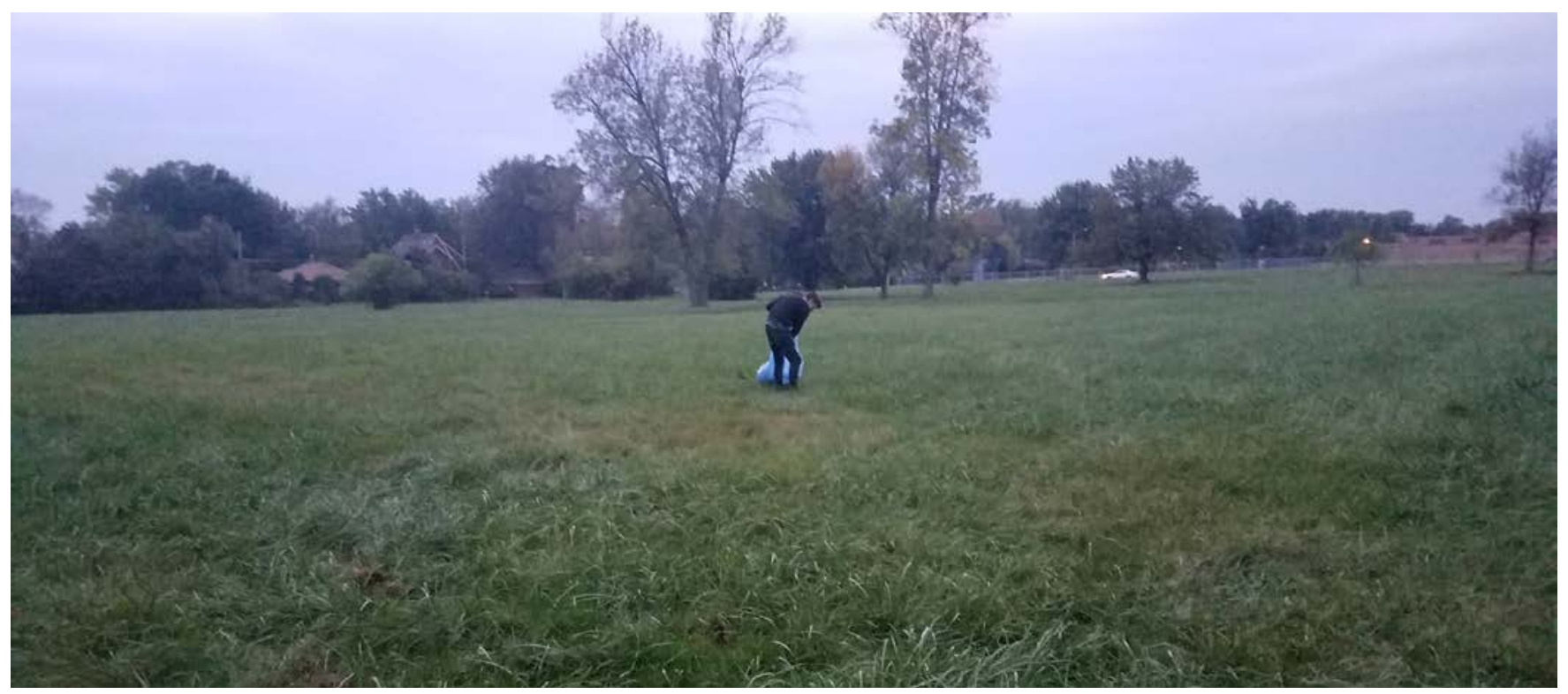

Figure 1. Photograph showing a student gathering grass clippings from a local park, to dry and use as pulp. Image credit: Georg Rafailidis

School of Arts (Germany), Daniels Faculty of Architecture at the University of Toronto (Canada) and SUNY Buffalo (US). Research has been undertaken in collaboration with Georg Rafailidis, Associate Professor of architecture at SUNY Buffalo, and is on-going.

\section{SOURCING MATERIALS}

In the research, the idea is that the material options should be broad. Any cellulose-based material that can be obtained in large quantities at either little or no cost is a candidate for the casting process. The first thing that students do, in the research studio, is gather potential materials, that fit the three criteria, for evaluation. Materials that have been sourced and gathered include twigs, wood shavings, grass, cat tail flower, flax fibers and seeds, hemp, denim, corn husks, paper from recycling bins, cardboard boxes, kraft paper (from paper bags) newspaper, cellulose insulation, toilet paper and paper towel, tissue paper and potatoes, among others. There is a scavenging aspect to the material sourcing phase of this research; materials should be common and found around us, not bought. In this respect, the process allies itself with material sourcing for another type of ephemeral architecture - bird's nests, wasp nests and other animal habitats which are self-made using materials readily available, light, and able be digested into a composite structure which lasts one season.

After examining the broad palette of potential materials that were gathered, two additional criteria were added: materials should be available throughout all seasons and materials should be easily transformed into pulp. These two additional criteria meant that materials like corn husks, available within a very limited time window in mid-fall in WNY, were not pursued. Twigs and wood shavings, likewise, were not pursued as they do not have a fibrous composition and cannot be easily transformed into a pulp mixture for casting using low-tech means.

In addition to the materials sourced by the students, the design research has benefitted from a bale of cotton linters donated by Georgia Pacific in Atlanta, GA. The bale consists of several compressed sheets of linters, which are commonly used in paper making. This particular type of linter was commonly used in making paper money. The large quantity of cotton fibers provided a base for many hybrid fiber mixtures that students have tried since the design research work started in 2016.

\section{STUDYING THE MATERIALS}

In all four research studios to-date, a period of research into the materials has preceded any hands-on work. The idea is that we should never immerse ourselves physically in materials that we don't understand. Gathering insight into the chemical composition of materials, their fabrication and their microstructures also provides a baseline physical understanding about the materials that helps when beginning hands-on work.

Students undertook "What exactly is...?" research studies, sharing the findings with the entire class in order to built-up collective knowledge. The presentations aimed to explain key terminology related to paper and fibers. Students learned more about cellulose, where it's found and in what concentrations. They also discovered the two basic categories of paper products: cotton-based and wood-based.

One aim, during this phase, was to connect abstract information about source materials, harvesting and manufacturing processes, and the chemistry of materials, to the physical samples themselves. In that way, empirical 


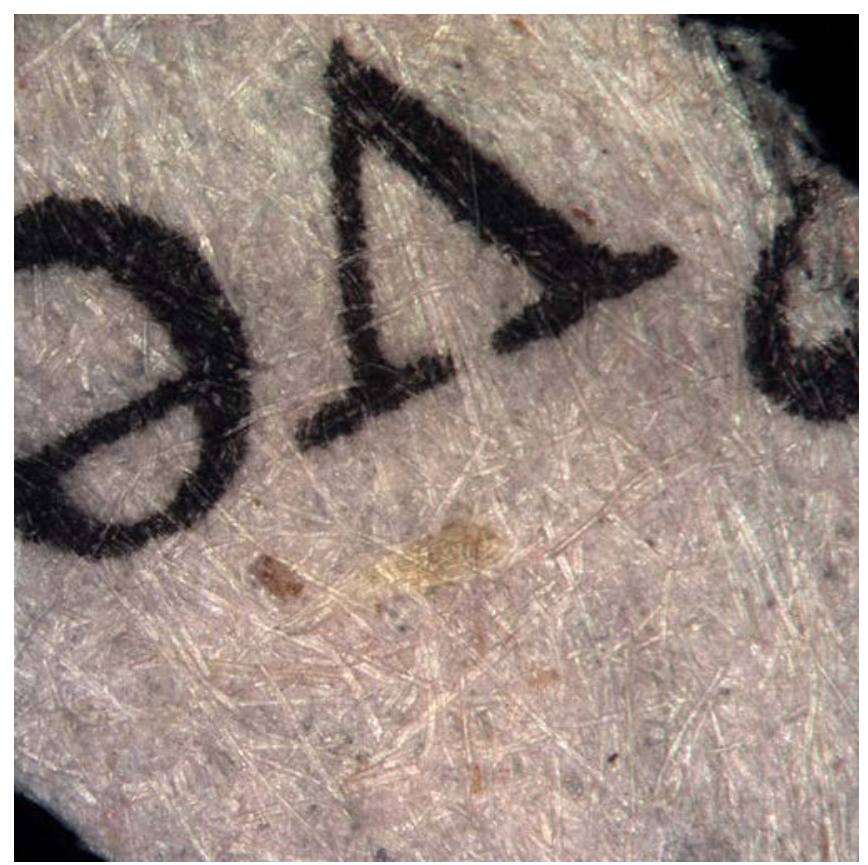

Figure 2. Stereomicroscopic image of newspaper taken at the Special Instruments Center, SUNY Buffalo for PULP graduate research studio, 2019.

observations could be knit together with more abstract facts about different materials. For instance, the physical weakness of toilet paper was knit together with the discovery that it's made with low-grade, recycled wood-pulp. Wood pulp fibers are shorter and weaker than cotton pulp fibers. The ephemeral nature of toilet paper made sense in light of these discoveries.

Further insight into the materials was gained through microscopy. Students used both the scanning electron microscope and a stereomicroscope at SUNY Buffalo to take images of the microstructures of their materials at different levels of magnification. Images were taken with the scanning electron microscope at between 100 and 300x, while the magnification used with the stereomicroscope was around 50x. Both sets of images enabled us to see and better understand key physical attributes that characterize paper such as the mechanical interlocking of the fibers.

\section{MAKING PULP}

Materials worked with to-date can be placed in two categories: recycled paper products and self-harvested fibers.

The recycled paper products include materials such as printer paper salvaged from garbage or recycling bins, paper towel, toilet paper, cardboard boxes, kraft paper, newspaper, cellulose insulation and tissue paper. These materials were generally easy to transform into pulp, which is a thick, slurry mixture made of a suspension of the paper fibers in water. Paper was either shredded or ripped-up manually before soaking in pails of water. After soaking, the paper was further broken-up using a universal mixing paddle drill attachment.

Self-harvested fibers, like grass and cat tail flowers, were considerably more labor-intensive to transform into pulp. In traditional paper making, a caustic basic solution, or chemical bath, is used to break-down plant fibers. In working with the cat tail flower, boiling was used as an alternative to the chemical process. Large pots of the cat tail flower were boiled for several hours and blended in small batches with a kitchen blender in order to achieve a pulp-like suspension.

A third category of materials used in the research studios to-date includes woven fabrics. Cotton jersey and denim were both used in projects and required the most labor to break-down into pulp compared to the recycled paper and self-harvested fibers. The denim, for example, was cut into $1 \times 1 \mathrm{~cm}$ pieces before being boiled for several hours and pulled-apart by hand. Sheets and forms cast with the denim pulp retained the soft, fabric-like quality, but due to the thick and long character of the fibers, were also heavier than cast

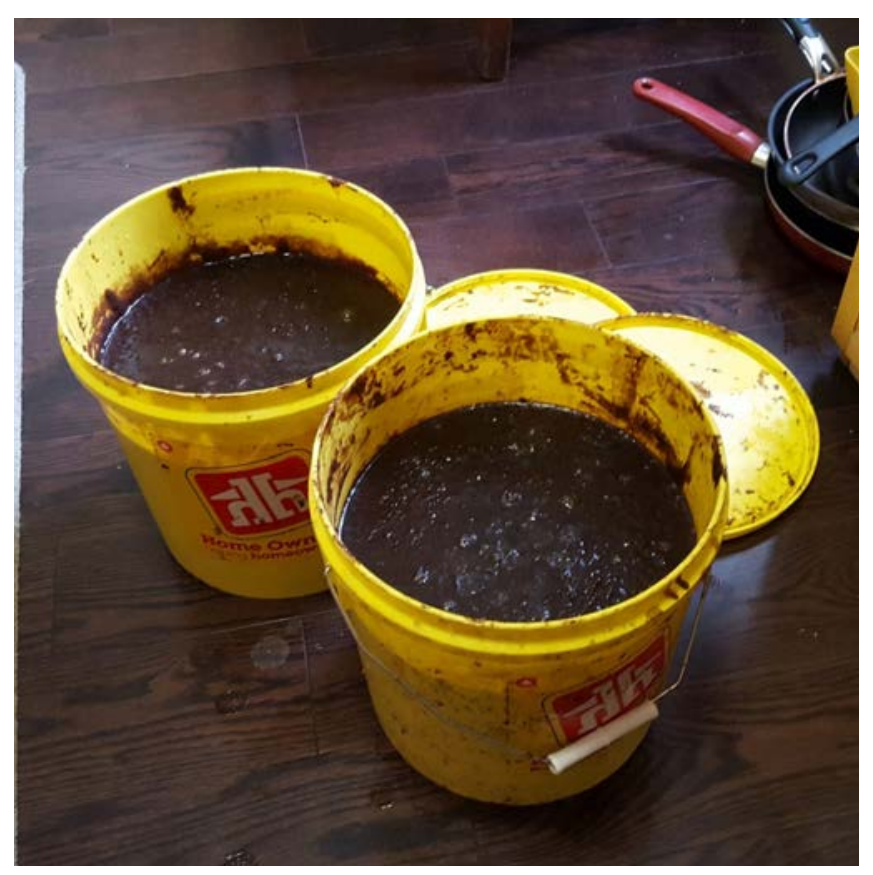

Figure 3. Buckets of cattail pulp prepared for casting. Image credit: Grace Shih-En Chang, Hoda Farahani, Jeremy Keyzer

paper. Because fabric waste (known as "shoddy") is a known problem, research into digesting this waste into thin-shell cast forms is on-going.

\section{CASTING PAPER SWATCHES}

After looking into the backstory of their cellulose materials what they're made out of, where the ingredients come from 


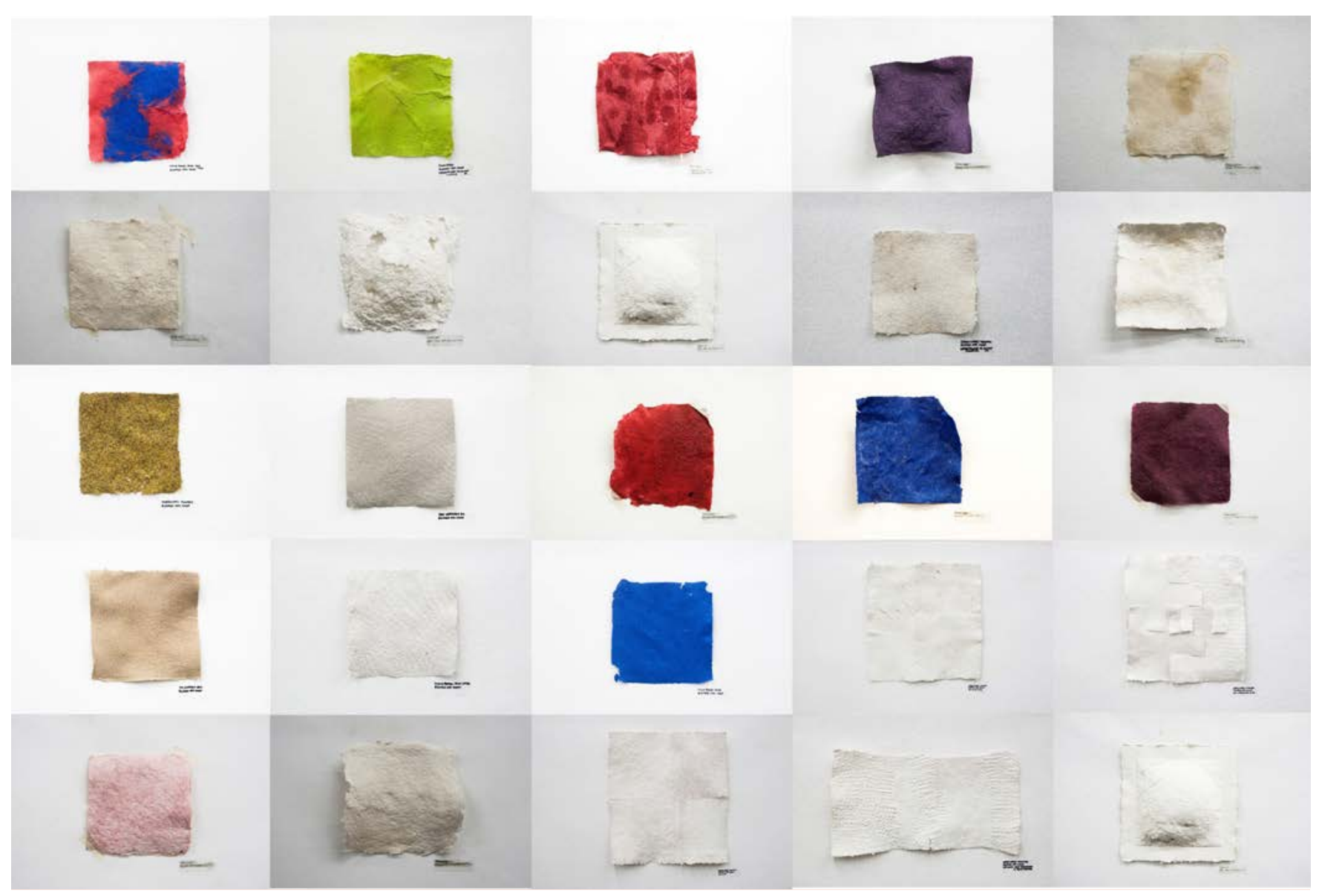

Figure 4. Swatches fabricated by one student group (students: Lemma Al-Ghanem, Ashwini Karve) examining different fibers, fiber mixtures, connecting more than one cast sheet, three dimensional deformation of swatches. Image credit: Lemma Al-Ghanem, Ashwini Karve.

and how they're processed - students were introduced to basic papermaking. This part of the process - making swatches - provided the backbone to the research course. The swatches were the tests that enabled us all to see and examine how different fibers performed when cast as sheets. The swatches, made using a traditional mold and deckle and approximately $8 \times 11$ inches each, were also a manageable scale in which to experiment with different thicknesses of cast paper, different methods of joining separate swatches, combining fibers, and beginning to deform the cast planes three dimensionally. Material and formal tests in the swatches prepared students as we strategized about how to scale-up toward a full-scale cast paper shell. Swatches were also used to look at ways to decrease the hydrophilic nature of paper, by either applying or combining different greasy substances into the pulp mixture.

\section{SCALING UP TO THREE-FOOT SPANS}

The scaling-up process was done incrementally. From the swatch size, students looked for structural logics that made sense with the thin, cast paper. As the spirit of the studio was to create as little waste as possible, the conventional approach to constructing formwork was out of the question. The entire idea of formwork had to be re-thought and this was handled differently from group to group. Different techniques manipulated the cast paper in moist and dry conditions.

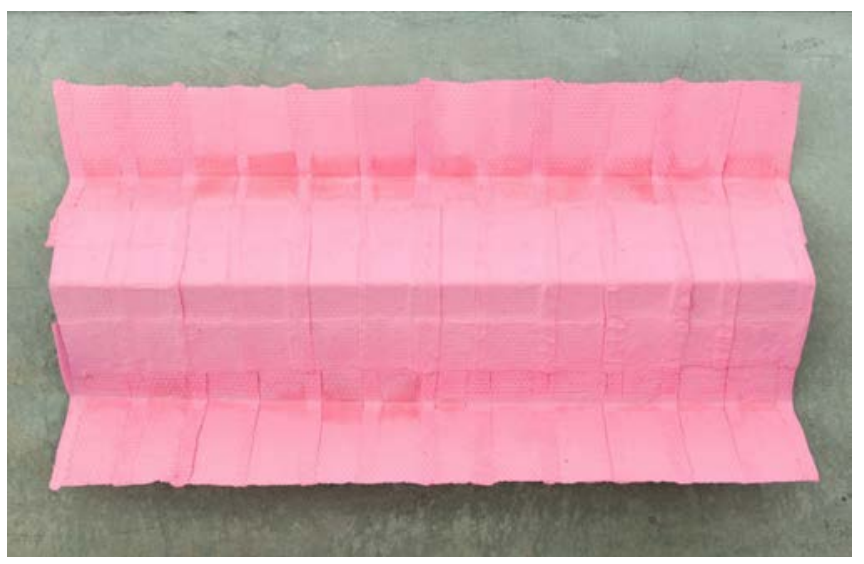

Figure 5. Example of a three foot span made using an additive approach of laminating individually cast sheets together while still moist. This particular span was cast using "found formwork" - geometries found in the studio interior that would lend structural properties to the cast spans. Students: Nashid Chowdhury, Vicky Pilles. Image credit: Georg Rafailidis. 


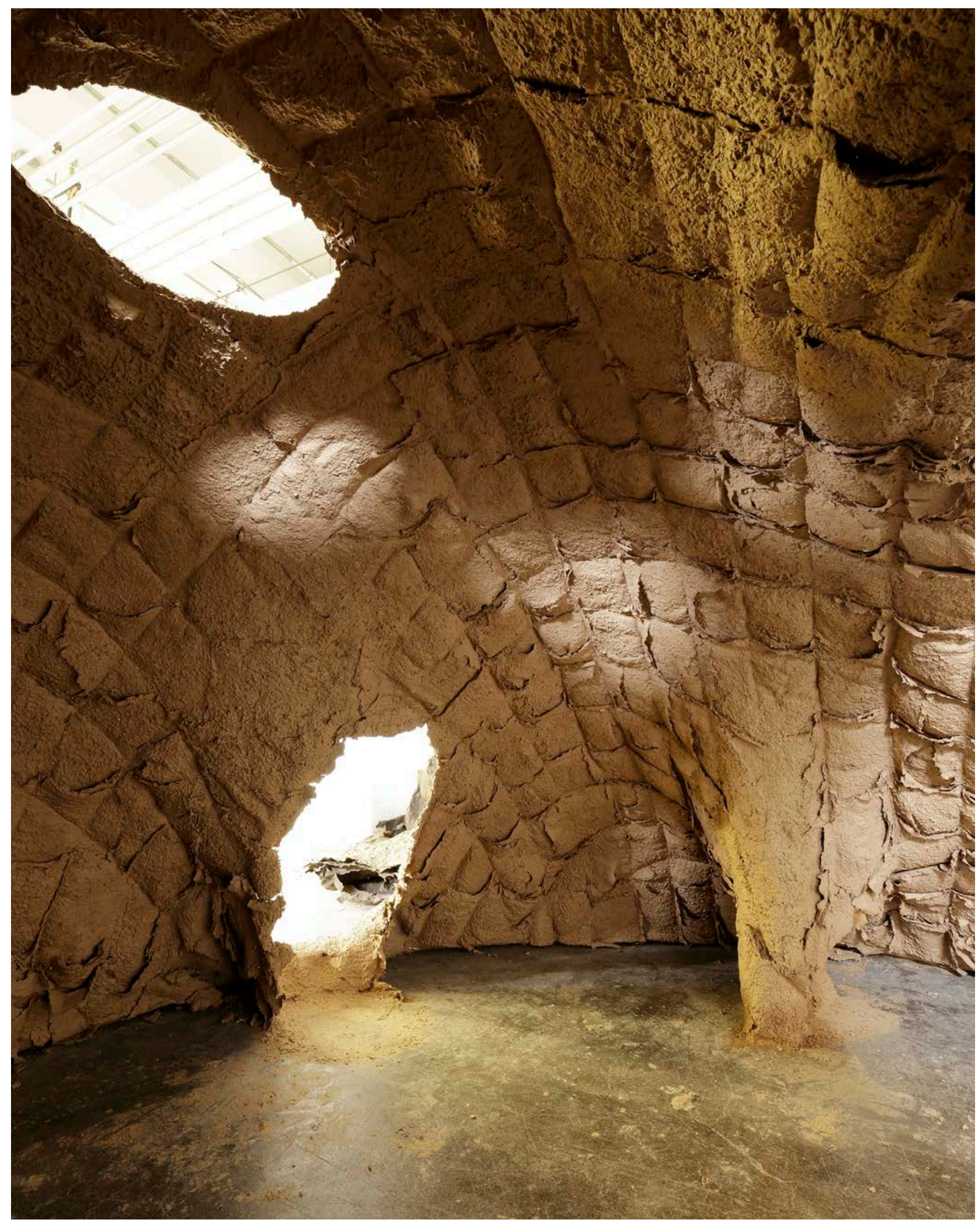

Figure 6. Photograph showing the interior of the cast cardboard shell after the formword had been "eaten" out. Image credit: Georg Rafailidis. 
In one project, spots around the building were used as "found formwork" to create three dimensionally stable cast paper shells; paper was cast onto corners, stairs and furniture so that the structural geometries of those spatial situations were imparted to the sheet material. Corrugated and curved surfaces, in particular, contributed rigidity to the cast paper forms. Other groups used a combination of found formwork and the naturally occurring ripples in the hanging fabric that became structural when dry; large sheets were slumped, for instance, over tables or pails.

Large sheets of cast paper were also manipulated dry using folding patterns to achieve three dimensional forms.

The idea in this intermediary scale was to find ways that were material specific and light on formwork to scale-up and create a three-foot span. What became clear during this phase was that each material, though cellulose-based, had very particular behaviors when cast into sheet form. Students needed to use their structural intuition and work in a trial-and-error way to see what behaviors and potentials they could exploit in their specific material. For example, the high degree of shrinkage in the large scale cast grass sheets resulted in considerable surface deformity that, though irregular, gave the sheets more rigidity than flat sheets.

Another example of material-specific behavior was bagasse, which is sugar cane residue. This material, with granulated sugar as an additive, needed to be formed at a very specific time as it was drying in order to achieve a rigid, draped form. In scaling-up, other student groups opted to try ephemeral formwork like a balloon. Unlike other processes, using this type of formwork, depending on how it was handled, could result in more predetermined, controlled three dimensional forms.

\section{ROOM-SIZED CAST PAPER MONOCOQUE ENCLOSURES}

From the range of techniques tested to make a three-foot span, various approaches have been taken to scale-up to fabricate full-scale cast paper shells. These approaches are characterized by their structural typology, approach to formwork and, of course, material composition. Here, I'll share three large-scale cast paper shells that each used a very different set of variables.

\section{EXAMPLE PROJECT 1: CANNIBALISTIC CARDBOARD FORMWORK/SHELLENCLOSURES}

Students: Eric Chandler, Elias Kotzambasis, Cody Wilson

The first large-scale cast paper shell is notable for its cannibalistic approach to formwork. This project worked with pulp made from used corrugated cardboard boxes. The form for the shell was generated using Rhino Vault, a plugin for Rhino, which gives catenary geometries in digital model form. The templates for the ribs were projected onto the wall to scale them up, traced onto the cardboard and cut-out by hand. The dimension of the grid used in the formwork was determined by the deckle - the traditional papermaking frame and screen used to cast single sheets of paper. The formwork grid was slightly smaller than the mold and deckle used by this group, so that individual sheets of cast paper would create an overlap and bond as they were laid, one by one, atop the formwork. This particular project is notable because of its strategic use of both cast paper sheets and sprayed pulp. Whereas many projects switched to the use of a texture sprayer for the full-scale paper shell fabrication, this approach used a layer of tiled paper sheets as a base. The sheets were made rapidly using a self-made machine consisting of a shopvac attached to a mold and deckle. The process of layering the individual tiles atop the ribs was time sensitive since we knew, from swatch tests, that moist cast paper doesn't bond with dry paper. On top of the tiled sheet layer, an additional, thin layers of cardboard pulp was applied using a texture sprayer. The unexpected twist in this project was that the additional pulp for the several sprayed layers was made using the cardboard formwork, which was torn out bit by bit until the vault was hollowed-out and substantially thickened from the cast layers.

EXAMPLE PROJECT 2: WIND-FORMED CATTAIL SHELLS Students: Grace Shih-En Chang, Hoda Farahani, Jeremy Keyzer The second of three projects that I'll share contrasts from the cardboard project in its material selection and more unpredetermined formal outcome. Pulp was made, in this project, from the cattail flower. As with most natural fibers harvested from their source, the material had to be boiled for several hours in order to break-down into a slurry consistency that could be manipulated further as cast sheet material.

The material was strained and blended repeatedly. Compared to paper pulp, the cattail pulp was finer and didn't accumulate into a sheet using the mold and deckle used in traditional paper 


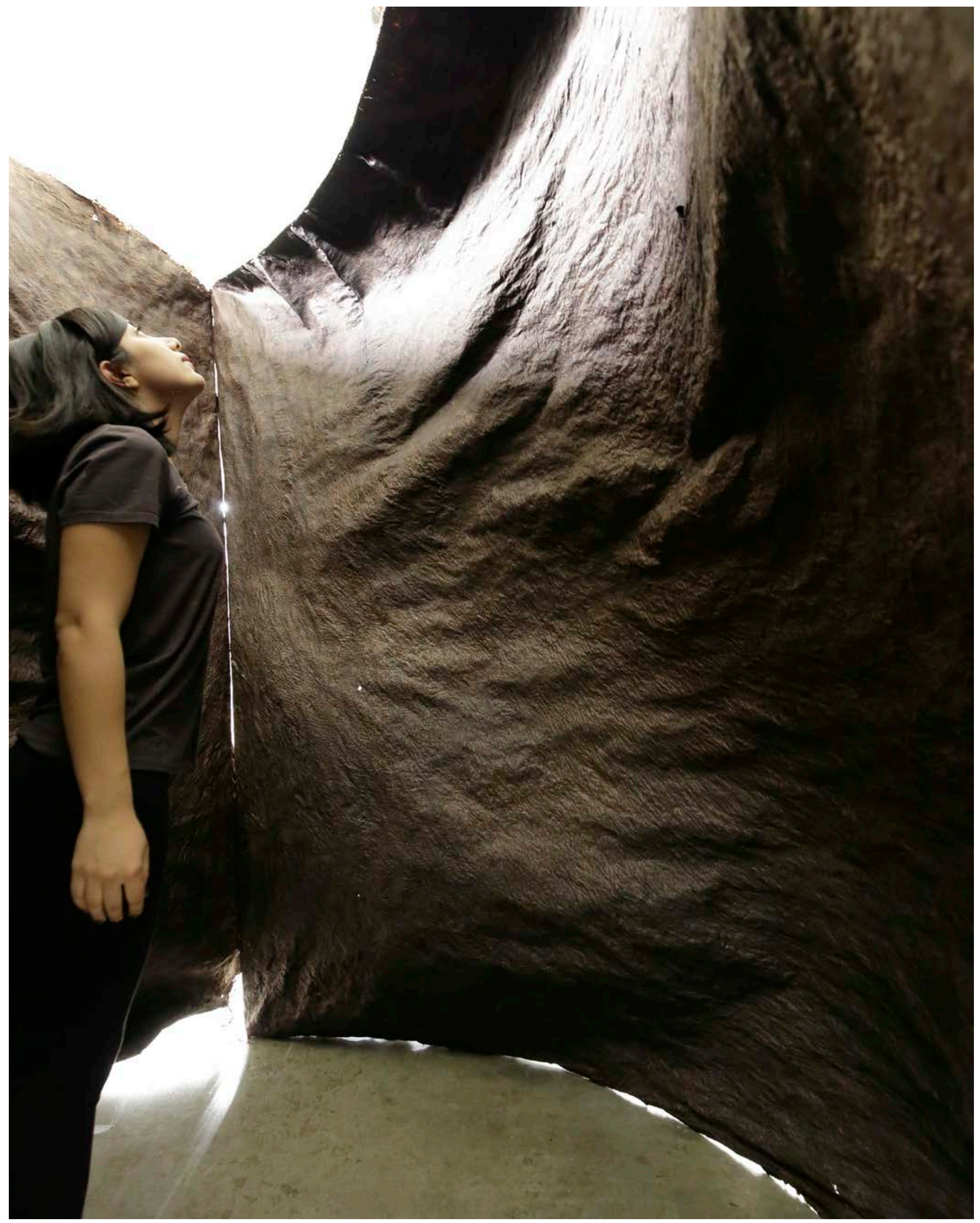

Figure 7. Photograph showing the cattail shell enclosure.Image credit: Jeremy Keyzer. 
making. Cheesecloth was used as a substrate to compensate for the lack of mechanical interlocking in the cast, fine cattail fibers. Students used a combination of painting the pulp onto the cheesecloth with fans constantly running in order to help the sheets dry and to aid in air circulation in general, since studio environments for this type of work were consistently very humid. In order to achieve a degree of rigidity that allowed the panels or sails to sit self-supported on the ground, pulp was applied daily for around 10 days. Ultimately the fans required to help in drying and air circulation had an impact on the three dimensional deformation of the cast planes. The structural typology, though hanging, could best be described as a wind-formed shell, since the three dimensionality of each plane was largely determined by the orientation and force of the wind driven by the fan or fans used for each sail.

\section{EXAMPLE PROJECT 3: CELLULOSE INSULATION CATENARY ARCHES}

Students: Craig Brozowski, Mike Hoover, Morgan Mansfield, Abigail Peters

The final project I'd like to share is the one, in the last three years of research, that was able to achieve the largest scale. The vaults produced in this project, reaching 9' in height, represent the furthest limits we've been able to push thin shell paper structures. The project was executed in the fall 2019 semester and the degree of refinement shown in the process is thanks, in part, to the knowledge accumulated in prior years of teaching this studio. The material used in the project is cellulose insulation. Cellulose insulation is newspaper treated with boric acid as a fire retardant. To make the formwork for the large catenary arches, the group used catenary lines derived from hanging string, and traced the lines onto plywood segments which were laser cut into arches. Cotton muslin fabric was then slung between the hung catenary frames which were suspended from the ceiling of the workspace. The fabric was bought by the $24^{\prime}$ long bolt for this project. Tubular foam was mounted on top of the wooden frames and the fabric was secured to the underside of the frames with bulldog clips. The same texture sprayer that was used in the cardboard project was used here. The newsprint blended easily into pulp and didn't clog the texture sprayer, as the cardboard and cotton linters tended to do. As with other projects, the ambient moisture in the workspace became a problem. At the time that this project was being executed in mid-fall, the heating system wasn't yet on. Fans helped with air circulation and a dehumidifier was set-up to help control the ambient moisture. Moist, cool air prevented the cast paper from drying and we did witness some instances of mold beginning to form. In the specific workshop conditions that we had, one vault was taking approximately one week to fabricate. Several layers of sprayed paper pulp were needed in order to achieve rigidity. The vaults were released from the ceiling and flipped over carefully. It took four people to carry one vault into another space for presentation - not because of weight but because of the form and the need to tip and twist through doorways. One of the considerations in designing the widths of the vaults was the need to transport through conventional-width doorways in the building. Nine catenary vaults were cast in total, in three different sizes, to allow the vaults to nest into one another and create a continuous enclosure.

\section{CONCLUSION}

This research and the outcome to-date is meant to shift our attitude toward decay-prone materials, and consider ways in which to harness this weakness to make temporary structures that are able and meant to disappear, and even add aeration and nutrients to the soil where they end up. More broadly, the research encourages a view of materials and assemblies as things that are constantly transforming instead of looking at materials as object that are fixed in a certain geometry or spatial composition. This research has been focused on demonstrating that it is possible to create large-scale monocoque structures using different methods that are each light on formwork and create little or no waste. The formal outcome of the research done so far shows that large-scale cast paper shells can be cast using a wide variety of source material and techniques, following different structural logics that best exploit or respect the capabilities of the material. Next steps of the research will look at the eventual decay of the structures as well as concrete use scenarios. 


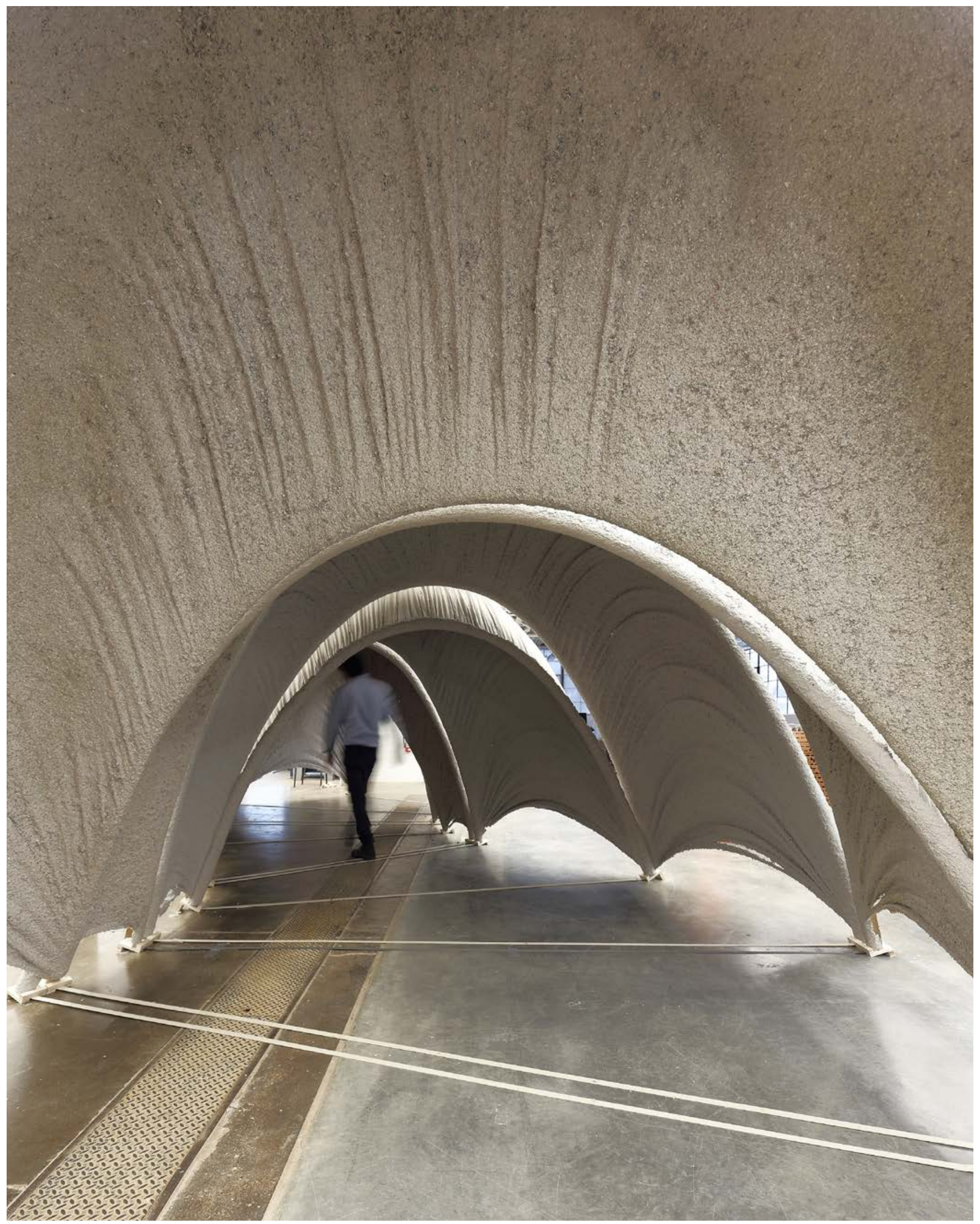

Figure 8. Photograph showing the interior of the series of cellulose insulation catenary arches. Image credit: Georg Rafailidis. 